patients, and who is not skilled in the use of very high powers of the microscope. These form a combination of qualities which will never be found largely represented in the members of the medical profession in any country. I believe the best thing that could be done in the present circumstances would be to send a selection of the young men chosen for the Indian Medical Service for six months to Rome or Catania, where they would not only get plenty of cases for continuous study, but would have the assistance of teachers trained in general pathology as well as specially expert as regards the parasite of malaria. Better still, perhaps, would be three months at Catania and three months at Rome, the best season at each being chosen. These men when sent to India could be specially attached to the medical schools of the large cities, charged with the duty of investigating the whole subject of malaria and of teaching the technique required by practitioners for diagnostic purposes. If a measure of this kind were carried through there is every reason to believe that India would in time contribute its quota to the furthering our knowledge of the disease in which, of all others, it has the greatest interest.

Queen Anne-street, W.

\section{THE VACCINATION LAWS.}

BF JOHN C. McVAIL, M.D., D.P.H.,

MEDICAL OFFICER OF HEALTH OF THE COUNTIES OF STIRLING AND DUMBARTON.

JENNER performed his first vaccination on May 14th, 1796. The centenary of this event has been the subject of national celebration at St. Petersburg. In Berlin, the capital of a country in which vaccination and revaccination are practically universal and small-pox practically nonexistent, Virchow and Koch and Von Bergmann and other men of world-wide reputation have held a great gathering in honour of a " benefactor of the universe." In Jenner's own country the circumstances are different. A Royal Com. mission on Vaccination has been in existence for nearly seven years and has not yet reported, the delay, it may safely be assumed, being due to the determination of the Commissioners to do their work thoroughly when they are at it. Compulsory vaccination in England has, however, in the meantime become a matter of local option, and in an increasing number of places the option, as expressed in the election of boards of guardians, is taking the form of noncompulsion. The growing neglect of vaccination in England is roughly indicated by the returns published annually by the Medical Department of the Local Government Board. The percentage of cases "not accounted for" - that is, infants who have neither been vaccinated nor died - was in 18728.8 in London and 4.5 in the rest of England. For London low-water mark was reached in 1881, when only 5.7 per cent. were not accounted for. For the rest of England the lowest year was 1875, when the percentage not accounted for was only 3. By 1888 the London and "rest of England" percentages had reached 10.3 and 8.2 per cent. respectively, and by 1891 (the latest year for which the data are available) the default had mounted to 16.4 and 12.9 per cent. respectively. No doubt for more recent years the results are still less satisfactory. These high figures are due mainly to neglect of vaccination in particular localities. In many places there is practically no omission to vaccinate, and such percentages as $0.0,0 \cdot 1$, and 0.4 are not unknown. But in Gloucester the "not accounted for" were in 1891 no less than 84 per cent. of the total, in Keighley 83, in Leicester and Northampton 80, in Oldham 78, in Luton 77, in Kettering 75, and so on. In the metropolitan districts the worst figures are for Mile-end old Town, 50 per cent.; for Hackney, 40 ; Bethnal Green, 38 ; Poplar, Greenwich, and Stepney, 19; and Paddington, Camberwell, and Westminster, 17. It is not my present purpose to discuss the value of vaccination and revaccination. $I$ believe that vaccination is of essential importance as a preventive of small-pox, and that perhaps no greater physical boon than the Jennerian prophylactic has ever been conferred on humanity. It is from this standpoint that the question of the vaccination laws is here viewed.

These laws are at present utterly unsatisfactory. Though called compulsory they do not compel. At the most they offer a choice between submission to vaccination on the one hand and payment of a money penalty on the other. The enforcement of this choice is in the hands of boards of guardians. whose practice is anything but uniform. While ore board insists on prosecutions and fines repeated regarding the same unvaccinated child so long and so often as a fixed age limit permits, an adjoining board may be satisfied with a single prosecution, and yet another may absolutely decline to take any action, while every election of guardians may suddenly reverse whatever custom has previously prevailed in the district. Elections ad hoo with all their recognised disadvantages are not infrequent. It thus results that the option to refuse vaccination without prosecution or penalty is not that of the individual, but that of the electoral division in which he resides, while if there is to be any option at all it obviously ought to be personal and not collective. Nor in districts where penalties are inflicted is the choice given between submission and penalty naturally a fair one, as the maximum fine, while bearing heavily on the agricultural labourer, is a trifle in the case of the well-to-do. Cheap martyrdom has temptations for many minds, and the vaccination laws present the opportunity for the desired notoriety. The fine imposed, however trifling, is not paid, imprisonment follows, and the subsequent release is celebrated by music from the local brass band, a demonstration, stump speeches, and a presentation. Carried away by the influence of what Carlyle, speaking Teutonically, calls " swarmery," such scenes result in the wholesale manufacture of anti-vaccination sentiment.

Another defect in the present law is that it says nothing whatever as to the thoroughness of the vaccinal operation. No fact in medical science is better attested than that the amount of protection depends largely on the sufficiency of the protective procedure. Every small-pox hospital bears witness to this, and the evidence applies to every period of life. In illustration it may be recalled that Dr. Gayton, who treated over 10,000 cases of small-pox in the metropolitan hospitals, found that in patients under fifteen years of age 706 who had "good marks" of vaccination had only 7 deaths among them, or less than 1 per cent.; while 2192 who had "bad marks," or though alleged to be vaccinated showed no marks at all, had 209 deaths among them, or over 9 per cent. Among 1504 cases admittedly unvaccinated at the same ages the deaths were 639 , or 42 per cent. The amended law should provide that whoever is vaccinated should be sufficiently vaccinated. No mere sham vaccination ought to be any longer possible to swell the ranks of those who, though registered as protected, are ready to succumb to the first approach of small-pox infection.

In addition to being both irritating and inefficient the law is utterly illogical. In 1853, when the first compulsory Act was passed, the need for revaccination was not sufficiently known. The recognition of its necessity has, indeed. largely grown from the experience of the protective results of infantile vaccination following on the operation of the law of that year. Primary vaccination had previously been performed at any age, but in 1853 the systematic protection of infants was begun, and we now have learned that that protection cannot be relied on to last in full amount throughont the whole of life. And here it may be desirable to note shortly what are the teachings of experience regarding the amount and duration of vaccinal protection. Loss of protection due to a first vaccination varies with varying circumstances. If the operation be performed in infancy then its infuence appears to be gradually weakened or diluted by the growth and development of the tissues and increase in bulk of the body. If it be performed later in life, when development is approaching completion or is already complete, its influence is much more lasting. If, therefore, reraccination be desirable, say, at ten years of age, it does not follow that a third and fourth vaccination should be done at twenty and thirty years of age, and so on. In Germany since 1874 vaccination has been compulsory both on males and females in infancy and again at eleven or twelve years of age. On healthy males a third vaccination is performed when they enter the army, but no evidence has yet been produced of excessive prevalence of small-pox among the female population of Germany through their want of a third vaccination. All the same, circumstances may arise--such as exposure to the infection of epidemic smallpot in a given population-rendering a third vaccination a wise precaution in adult life. if the second raccination has been done a very lono time previously. But the mention of ten to twelve years of age as the proper time for a second 
vaccination is apt to mislead. It is not to be assumed that the influence of infantile vaccination has disappeared by that age. The diminution of protective power is graduated both as to quality and time. The first manifestation of the drift towards small-pox consists in a return of susceptibility to the local effect of vaccination. Immediately after the completion of the vaccinal process there is no reaction to the insertion of vaccine virus. But by-and-bye a successful local vaccination becomes possible, so that it was found in Bordeaux that attempts to revaccinate at six years of age were in 40 out of every 100 children successful in producing the raccine vesicle. This does not mean that these children were susceptible to infection of small-pox in the ordinary way. In the Sheffield epidemic of 1887 in houses actually invaded by small-pox, and where the activity of the smallpox poison was manifested by the fact that about 90 per cent. of unvaccinated inmates were seized by the disease, it was found that among the vaccinated inmates of the same houses the attacks between ten and fifteen years of age were not 98 per cent., as in the unvaccinated inmates at that age, but only 25 per cent. ; and between five and ten years of age not 92 per cent., as in the unvaccinated at that age, but less than 10 per cent. Thus susceptibility of the - vaccinated to attack by small-pox returns at a later age than does susceptibility to the local effects of the vaccinal operation. But this is not all, for resistance of the vaccinated to death by small-pox outlasts very considerably resistance to attack by small-pox. At Sheffield under twenty years of age the percentage of deaths to attacks among the vaccinated ranged from 0.8 to 2.2 ; between twenty and thirty years the percentage was 5.4 ; and it was only over thirty years that the deaths reached 10.6 per cent. of the attacks. Yet such percentages both of attacks and deaths furnish abundant evidence of the need for revaccination. The liability of 25 per cent. of persons over ten years of age to be attacked, and the further liability of a small fraction of this 25 per cent. to die from small-pox, make the age of from ten to twelve years a proper time during which to renew the protection. I repeat, therefore, that the present law is utterly illogical in so far as it takes no cognisance of the need for revaccination. The protection of adults is as important as the protection of children, and whatever degree of insistence should be maintained in respect of infantile vaccination should also be maintained in respect of revaccination.

What degree of insistence ought to be maintained? That, no doubt, is one of the principal questions, if not the principal question, before the Royal Commission. The object of the Legislature should be to get as many persons as possible as well vaccinated as possible. That object, however, should be carried out in accordance with the spirit which governs present-day legislation in England. Russian methods are not for these realms, and the ways of the twentieth century will not be those of the tenth. There is even a difference since 1853, when the first obligatory enactment was passed. In this connexion due weight, but not more than due weight, must be given to the existing opposition to vaccination in many parts of the country. As regards compulsory vaccinal legislation, it is beside the point to argue that the antivaccination morement is carried on mainly by cranks, and that the public is simply being gulled by their persistent misrepresentations and mis-statements. All that, and much more, may easily be granted without altering the hard fact that a very appreciable number of people have been misled into doubting or denying the value of vaccination, and into the fear that vaccination may cause all kinds of unknown evils to their children. A still larger number of persons, while not themselves objecting to vaccination, object to the prosecution and penalising of their neighbours who have "conscientious objections" to the operation. In quite a number of localities, as has already been indicated, the law is at present a dead letter, and in at least a few of these it is probable that it could not be generally brought into operation again excepting by forcibly taking the child from the mother's arms and vaccinating the child in spite of her protests. It goes without saying that this course is repugnant to all present-day notions, and is in itself altogether objectionable.

The law, therefore, must allow some degree of option. How little and how much? In limine, a clear distinction must be drawn between the conscientious objector and the parent who is merely indifferent. The former, utterly wrong though he be, must have his scruples yielded to. On his behalf, and in the best interests of vaccination itself, I would abolish, not only imprisonment for unpaid fines, not only repeated prosecutions and penalties, but all prosecutions and penalties whatsoever directed against any man for refusal to allow vaccination of those for whom he is responsible. But what is to become of the protection of children whose parents are merely indifferent, to whom the whole question is the trouble, first of making up their minds to do a particular thing on a particular day and then of carrying out their intention so formed? For them, and also incidentally for the conscientious objector, the inconvenience attending on refusal of vaccination must be made at least as great as the inconvenience of going to the station for vaccination and a week later going a second time to have the vaccinated arm inspected. A national register of the unvaccinated should be established, and in order to get a name entered in this register the parent or guardian should have to go personally to a magistrate and make a sworn affidavit of his conscientious objection to vaccination. Having got a certificate from the magistrate he should then have to go personally to the registrar's office to have the necessary entry made there. No doubt the whole procedure could be made so elaborate as to be no less troublesome than that involved in the vaccination itself. It may be suggested here that a registration fee should also have to be paid, but this might be looked on as a fine, and my own view is that money fines for "conscientious objection" should be abolished.

Several advantages would belong to some such system as this: (a) It would be possible to enact that if vaccination were to be done at all it would have to be sufficiently done. There would be no hardship in insisting on a given number of insertions or of a given area of insertion when every parent would bave the right of declining vaccination altogether. (b) The result would be that those who were themselves thoroughly protected would have no cause for fear from small-pox among the unvaccinated. At present there is in the presence of small-pox constant anxiety as to the risks of children who have been only imperfectly and insufficiently vaccinated. (c) The different behaviour of small-pox as between the vaccinated and the unvaccinated would, as a consequence of the increased efficiency of the vaccinations and of the registration of the unvaccinated, be demonstrated even more clearly than at present, and statistics on a national scale would soon be available for the consideration of conscientious objectors whose judgment might be capable of being influence l by facts. (d) The supply of martyrs in the cause of anti-vaccination would cease. No satisfactory amount of local indignation and enthusiasm could be got up for a parent whose worst hardship would consist in the infliction of a fine for his refusal to call on a magistrate and a registrar to get his conscientious objections recorded. I do not suggest that all the leaders of the agitation would be either satisfied or silenced; but the opposition to vaccination, fanned as it is by tales of martyrdom and by the whole system of prosecutions and penalties for non-vaccination, would largely die out in spite of all efforts to maintain it. (e) But anotber consideration, much more important than any of these, remains to be adduced. Compulsion being abolished, the above-described alternative of vaccination, or registration of non-vaccination, could and should be made universally applicable, not only to infants, but also at ten or twelve years of age. In this way a national system of revaccination would be established on exactly the same lines as the proposed system of infantile vaccination. Whether an infant had been originally vaccinated or registered as unvaccinated, the law ought again to come into operation on the child reaching the age of, say, twelve years. If the child had been primarily vaccinated the option would now be between revaccination on the one band and registration of conscientious objection to revaccination on the other. If the child had been originally registered as unvaccinated the parent or guardian would now require to make the choice between primary vaccination of the child of twelve and renewed registration of conscientious objection. The ultimate effect of this renewed offer would be to add immensely to the total amount of vaccinal protection in this country, and I am inclined to believe that the gain in revaccination would more than atone for any diminution in primary vaccination which might be a first effect of alteration of the present law. However that may be, the new law would at least be logical in recognising the fact that revaccination is a necessity in addition to primary vaccination. At present there are hundreds of thousands of persons in this country who have a "pious opinion" that revaccination is an essential precaution 
against small-pox. But the precaution is delayed indefinitely owing to its never being brought before them as a duty requiring immediate performance. Cnder the system as here set forth this off-putting would come to an end. One administrative difficulty suggests itself as to this scheme-namely, the ascertaining of the exact time of each child's reaching the age for revaccination. How this is done in Germany I do not know, but with the aid of school boards and of the census (which, by the way, ought to be quinquennial and not decennial) there should be no insuperable obstacle. There is yet another set of circumstances in which the law should again interfere to obtain, with regard to unvaccinated and unrevaccinated persons, either a declaration of conscientious objection or submission to the protective operation. When small-pox threatens to become epidemic in any community the Local Government Board should have power to issue an order bringing into force this provision of the suggested Vaccination Act, and it is certain that great benefit would result. In any large city where agitation against vaccination has been active and effective, at any given date there might be found even under the new law a large number of children who had been registered as unvaccinated, and a large number of persons over twelve years old who had been registered as unrevaccinated. It may be urged that in the case of a local epidemic of smallpox even under the new law there should be a resort to penalties for non-vaccination, and that here at least it would be the bounden duty of the State to compel the operation. That is a view from which, on the whole, I would dissent. Having once adopted the principle that there should be no money penalties for non-vaccination the principle should be adhered to. But the fact is that in the presence of actual small-pox "conscientious objections" are apt to be set aside, and many parents would not care to take the responsibility of again refusing on behalf of their offspring the proffered protection. With regard to such persons it is easy to say, "Serve them right; let them get the small-pox"; but the object of the State must be to afford protection wherever it will be accepted, even to those who, in the absence of the bane, have declared their disbelief in the antidote. And always it has to keep in view that the main sufferers from anti-vaccination are the little children, the helpless victims of the wrong-headedness of their parents. In a stricken community the offer of vaccination would not of course be withheld even from adults who already, both in infancy and at twelve years of age, had undergone the operation.

In revising the vaccination laws it is important that everything possible should be done to allay fears as to possible evil consequences from the operation. In England the total number of births in any year is about 900,000 and the number of deaths from all causes under one year old is about 140 for every 1000 births, or, in other words, of 1000 children born only 860 reach one year of age. The mortality is greatest of all in the first months of life. The age fixed by law for vaccination in Fngland is under three months, and as the vaccinal process, dating from the operation to the fall of the crust, occupies about three weeks, it is obvious that a considerable number of deaths from ordinary infantile ailments must occur " under vaccination," and it may be assumed that, at least in places where there is an organised opposition, in the case of many of these deaths vaccination has to act as the scapegoat. That will be the case to some extent no matter at what age the operation is performed, but there is no reasonable doubt that vaccination would be less blamed if the operation were deferred until death had done its work among the weakly and ailing under one year of age. Among the survivors most of the cases of skin eruption due to dentition would by that time have developed themselves, so that here, too, the post hoc propter hoc argument of vaccinal origin of such cases would not be available. In Scotland the vaccination age is six months, not three months, as in England, and there certainly is much less opposition to raccination in the northern kingdom, though to what extent the age question is a factor here it is difficult to say. Anyhow, there is a sentimental objection to operating on babies a few weeks old, and I am of opinion that raccination should not be insisted on until the child is about to complete its first year. In presence of small-pox, however, the Local Government Board should have power to issue in any locality an order fixing the compulsory age at three months or six months. In Germany the operation has to be done during the first calendar year following the birth of the child. Thus a child born any time between Jan. 1st and Dec. 31st, 1896, must be vaccinated some time between Jan. 1st and Dec. 31st, 1897, so that the average age is probably a little under eighteen months.

Thile there is nothing of any importance that human beings can do which is absolutely without risk of some sort vaccination is yet an exceedingly safe proceeding. Taking all the death registrations in which it is mentioned as having any part in the matter (and in many of such cases it is a mere incident), there are not much more than onetwentieth of the deaths set down to it that are set down to the suffocation of children by bedclothes. Nevertheless, as a result mainly of an active propaganda, vaccination has in some districts to bear the blame of many of the ailment which befall children in the course of their ordinary upbringing. There is in the minds of some people an impres sion that "humanised" lymph is apt to convey all kinds of diseases from the vaccinifer to the vaccinee. Among meàical men no such fear prevails, and in their own families they no not hesitate to use lymph taken from a healthy child But there is no reason why consideration should be refused even to this ill-founded fear. In calf-lymph we have an inoculative material at least equally safe (theoretically even safer) and not necessarily less convenient. On the Continent (where probably arm-to-arm vaccination was not performed with the same care and caution as in this country) calf lymph is now almost universally used. It is quite free from one particular risk, which though almost infinitely unlikely of realisation is yet most serious when realised. In one respect calf lymph possesses a great advantage over arm-toarm lymph; in emergency it is capable of indefinite multiplication, so that material for the vaccination of a whole city can be prepared within a very short time by the simple expedient of vaccinating from one or two calves as many more calves as may be required for the purpose. With humanised lymph this is impossible, as the whole stock obtainable on any one day from the largest vaccination station in the kingdom would suffice for only a very limited number of fresh operations. In an epidemic, moreover, many of the vaccinees are adults and these should never be used as vaccinifers. When this question of the substitution of calf lymph for humanised lymph was first raised in England it was objected that a considerable proportion of the insertions of calf lymph would fail in producing proper vaccine vesicles - that the insertionsuccess would not be so great as in arm-to-arm vaccination. So far as calf lymph is concerned this fear has been found groundless. An experienced vaccinator can produce good vesicles up to within a fraction per cent. of his insertions. With stored calf lymph, however, the success is probably not so great. On the other hand, it is urged in favour of preserved calf lymph that the glycerin with which it is commonly mixed has the effect of destroying extraneous infection, such as that of erysipelas, which is about the only genuine risk that ever really does accompany vaccination, and, rare as is serious vaccinal erysipelas, it is yet very important that so far as may be it should be avoided. The point is one on which I do not venture to express an opinion. but no doubt the comparative merits of fresh calf lymph and stored calf lymph will be considered by the Royal Commission. In France fresh calf lymph is used, and it is held there that careful antiseptic precautions have left no fear or risk of erysipelas. If this be so then probably fresh lymph ought to be selected. In the French vaccination system the vaccinator proceeds from village to village, previous public intimation having been given of his itinerary. The calf to be used is conveyed in a specially constructed vebicle and the lymph is applied directly from calf to arm.

By what machinery could such a scheme of national vaccination as is here adrocated be carried out? At present in Scotland, unless for certain exceptions in some of the largest cities, every medical man vaccinates the children within his own practice, and as a family medical man is selected on account of the confidence which is felt in his skill there is much less tendency to rush to post hec conclusions than in England, where from one-half to two-thirds of the vaccinations are done by public vaccinators specially appointed. Yet if calf $1 \mathrm{ymph}$ nere to be generally adopted it would be a matter of practical necessity that in any calfto-arm system the work should be done by medical men specially appointed and even confined to vacination duty. At present in England the local authority in charge of public vaccination and public vaccinators is the board of guardians. This is an anomaly which ought to be remedied. Taccination is a public health provision and ought to be 
under the charge of a public health board. When small-pox prevails it is absurd that the authority which has charge of hospital arrangements, disinfection, \&c., should have to go hat in hand to the Poor-law guardians with regard to increase of facilities for vaccination, especially as the two bodies do not always see eye to eye on so essential a preventive measure. But as to the authority which ought to supply the calf lymph I am not quite so clear. It is out of the question that every public health department, urban and rural, should maintain a calf lymph establishment of its own. The duty ought to be entrusted to the Local Government Board or to the county councils, and the experience of foreign countries will be available to the Commission in deciding which course would be the more efficacious and the more economical. Personally, I would be inclined to place the responsibility as high up as possible-with the Whitehall Board rather than with county councils; but it is conceivable that there might be practical difficulties with regard to the transportation to remote districts of vaccinated calves. English counties are of such diverse areas and population that they do not strike one as suitable administrative units for such a purpose. No doubt combination of counties could be made, but joint boards are not free from objection, and the whole country might as easily be divided into large districts for central administration as grouped into counties for joint county government. Even under the latter arrangement there would have to be supervision from Whitehall, and I see no sufficient reason why Whitehall should not take charge of the whole business. The question, however, is for consideration by the Commission, which has at its disposal all available sources of information.

Such is the general scheme of legislation which seems to me best suited to meet the circumstances of the present time in this country. It would do away with all the irritation and ill-feeling consequent on prosecutions and fines, single or repeated, for neglect of vaccination; it would provide in the case of those who have conscientious objections a national register of the unvaccinated; it would at the same time be designed to prevent non-vaccination as a result of mere parental indifference; it would offer calf lymph to all who might choose to have it; it would (subject to the option of the register) provide for revaccination at twelve years of age and also in presence of epidemics in particular communities it would insist that raccination when done at all should be efficiently done; and it would postpone to twelve months the age at which primary vaccination should be formally demanded. Against this scheme it may be urged that its first and immediate effect might be to produce a diminution in the amount of infantile vaccination. This would be easier to urge than to establish, for it is to be kept in view that in many places at present where boards of guardians take no action no defivite pressure is brought to bear on the merely indifferent. It is not to be supposed that in Gloucester, Keighley, Leicester, Northampton, \&c., 80 per cent. of the population are conscientious objectors, and great part of the neglect is no doubt due to sheer carelessness or to the fashion of the locality. Possibly, however, taking the country as a whole, the fear might be realised that there would be, as a first result of the new law, some diminution in the amount of infantile vaccination with, as a result. recrudescence of small-pox and loss of lives which vaccination would have saved-lives mainly of helpless children suffering Geath for the folly of their parents. But the fact must be faced that even at present, material is accumulating for a small-pox epidemic and it almost looks as if the death toll were already beginning to be exacted. The further fact must be faced that owing to a combination of causes which have been already indicated there has been arising in this country a considerable amount of prejudice against the present vaccination laws. There is a deliverance of Burke which has been already quoted by a foremost opponent of vaccination and which will bear requotation here: "It would be dreadful indeed if there were any power in the nation capable of resisting its unanimous desire or even the desire of any very great and decided majority of the people. The people may be deceived in their choice of an object; but I can scarcely concive any choice they can make to be so very mischievous as the existence of any force capable of resisting it." It is hard to say exactly where Burke would have drawn the line in regard to the present question. Where does the duty of the State end to enforce on children what it believes to be an important sanitary measure, and where does the right of the warent with conscientious objections begin, to refuse to submit his child to what he supposes may be a very dangerous proceeding? We have had compulsory education since Burke's day, and I do not for a moment believe that the majority of the people are opposed to vaccination, but I do believe that the opposition has become so considerable that it would be unwise to attempt universal enforcement of vaccination. If it is too much to hope that the operation of the scheme sketched in this article would not diminish infantile vaccination (and even that hope I would not care to abandon until the scheme had been tried), it is at least a reasonable expectation that revaccination would be much more largely resorted to than heretofore, and that loss of child life might in the national economy be compensated for by saving of adult life. And though it is a hard thing to say, the prevalence of small-pox in the young would have this beneficial effect, that it would educate the parents of this generation into an acquaintance with, and a horror of, small pox which are almost unknown nowadays owing to the very success of the Jennerian prophylaxis. The ultimate result might therefore be that vaccination would once more become almost universal and that revaccination would obtain a prevalence which it never has yet possessed in these realms.

Perhaps, before closing this article, I should refer to a pro. posal which is coming to be more and more mentioned in connexion with the prevention of small-pox-namely, compulsory hospital isolation. Let it be observed, in the first place, that this, though it would be a most useful adjunct to any incomplete and partial system of national vaccination, could never become a substitute for vaccination. Even putting aside the known fact that small-pox hospitals have often themselves proved centres of infection to surrounding unprotected populations, it is obrious that such a hospital requires a staff of attendants, and that these, if not themselves protected, would fall victims to infection, and that they in their turn would require another staff of attendants, and so on indefinitely ; but if it be urged that in the absence of vaccination there would be no lack of surviving small-poxprotected nurses, I have no word to say in reply ; of patients, at any rate, there certainly would by-and-bye be a superabundance. Let it be observed, in the second place, that the compulsion of universal hospital isolation would soon raise up against it the same outery that has accompanied compulsory vaccination. Already, as the results of attempts at this method of prevention in ill-vaccinated neighbourhoods, we read of the burning down or other destructive injury by infuriated mobs of two intended small-pox hospitals in the West of England. And if the system of compulsory isolation which is at present only tentatively resorted to were formally established by law it would have directed against it all the artillery of anti-compulsion. Already some of the leaders of the anti-vaccination movement do not hesitate to state that their opposition to the one scheme would be as active as to the other. If, then, it be suggested that optional removal to hospital should be followed as a system of small-pox prevention, where do we land ourselves? Supposing that ninety go to hospital and ten stay at home, the ten will soon be surrounded by ninety more, and the ninety by nime hundred, and so on indefinitely. There would be no protection for anybody, while optional vaccination has at least the advantage that it protects those who choose to accept protection. The wise in the community must, therefore, in the meantime be satisfied with thorough protection of themselves and their offspring, and with doing their best to teach the truth about vaccination to their deluded neighbours, at the same time that the Legislature continues to bring to bear on the population at large such pressure as shall be most likely to produce, with regard both to vaccination and revaccination, a maximum of result with a minimum of friction. This is not a heroic remedy. Perhaps it is mere opportunism; but I believe that in the end it will most nearly fulfil the desideratum with which I set out, that in this country there should be as many people as possible as well raccinated as possible.

EAst London Children's HosptTal. - The anniversary dinner of the East London Hospital for Children was held on May 13th, at the Hôtel Cecil. Mr. John Aird M.P., presided. Cardinal Vaughan, in proposing the toast of "The Board of Management," said he was specially indebted to this hospital, all his clergy testifying to the great benefits it conferred on their extremely poor people. Donations amounting to $£ 1240$ were announced, including 100 guineas from the City Corporation. 